\title{
HIV/AIDS High Risk Behaviors and Necessity of Prevention in the Population of Birjand, East of Iran 2013 to 2014: A Population-Based Study
}

\author{
Gholamreza Sharifzadeh, ${ }^{1}$ Asghar Zarban, ${ }^{2}$ Morteza Hajihosseini, ${ }^{3}$ Ghodsiyeh Azarkar, ${ }^{4}$ Kambiz
}

Mahdizadeh, ${ }^{5}$ Majid Shayesteh, ${ }^{6}$ and Masood Ziaee ${ }^{4,}$

${ }^{1}$ Social Determinants of Health Research Center, Birjand University of Medical Sciences, Birjand, Iran

${ }^{2}$ Antioxidant and Metabolism Research Center, Birjand University of Medical Sciences, Birjand, Iran

${ }^{3}$ Cardiovascular Diseases Research Center, Birjand University of Medical Sciences, Birjand, Iran

${ }^{4}$ Infectious Diseases Research Center, Birjand University of Medical Sciences, Birjand, Iran

${ }^{5}$ Deputy for Health, Birjand University of Medical Sciences, Birjand, Iran

${ }^{6}$ Birjand CDC Manager, Birjand University of Medical Sciences, Birjand, Iran

"Corresponding author: Masood Ziaee, Infectious Diseases Research Center, Professor of Infectious Diseases, Department of Internal Medicine, Faculty of Medicine, Birjand University of Medical Sciences, Birjand, Iran. Tel: +98-9151613942, E-mail: dr.m.ziaee@gmail.com

Received 2016 January 01; Revised 2016 February 26; Accepted 2016 March 13.

\section{Abstract}

Background: Human immunodeficiency virus (HIV)/ acquired immune deficiency syndrome (AIDS) is a major threat for public health around the world.

Objectives: This study aimed at investigating the prevalence of HIV/ADIS high risk behaviors and necessity of prevention in the population of Birjand, East of Iran.

Methods: This population-based study was conducted on 5235 subjects from Birjand, East of Iran, during years 2013 to 2014 . Subjects were asked to complete a checklist including gender, marital status, and history of drug injection, tattooing, unsafe sexual contact, imprisonment, dental surgeries, bloodletting, and blood transfusion. All subjects were tested by commercially available enzyme-linked immunosorbent assay (ELISA) kits to detect Anti-HIV antibodies (HIVAb; Genscreen $®$ plus HIV Ag-Ab, Bio-Rad, Matnes la coquette, France). The chi-square test was performed and $\mathrm{P}<0.05$ was considered statistically significant.

Results: Prevalence of HIV was zero. Also, result of the study showed that $9(0.2 \%)$ subjects had a history of drug injection, 81 (1.5\%) history of tattooing, $44(0.8 \%)$ unsafe sexual contact, 39 (0.7\%) history of imprisonment, 1709 (32.6\%) history of dental surgeries, and 802 (15.3\%) history of bloodletting. History of drug injection, history of tattooing, unsafe sexual contact, history of imprisonment, and history of dental surgeries showed a significant relationship with gender.

Conclusions: It is recommended to increase knowledge about HIV/AIDS behaviors especially in low risk populations to prevent the occurrence of new cases.

Keywords: High Risk Behaviors, Prevent

\section{Background}

Human immunodeficiency virus (HIV)/ acquired immune deficiency syndrome(AIDS) is a major threat for public health around the world and is growing annually (1). Human immunodeficiency virus infection is detected by blood tests for HIV antibody, however, only a small proportion of people have an HIV test; this is a reality in developing countries, which have limited access to health care services (1). World health statistics showed that HIV prevalence has increased from 2003 to 2013 with a gentle slope (2). Haghdoost et al. indicated that HIV prevalence in Iran was between 7.14 to 15.95 per 10000 individuals in 2010, also new HIV infected cases were between 3.9 to 12 per 10000 individuals in 2014 (3).
The HIV/ AIDS risk is growing in Iran. The prevalence of HIV infection has doubled in Iran in the past 3 years (4). According to United Nations ADIS committee reports, the prevalence of adults aged 15 to 49 was $0.1 \%$ in Iran during year 2014. Some of the well-known HIV high-risk behaviors are history of injection drug use, needle/syringe sharing (5), razor sharing, tattooing, unsafe sexual contact (6), and imprisonment (7). According to the importance of HIV/AIDS in any specific geographic region, this research was conducted for the first time on the entire population of Birjand, (East of Iran) during year 2014 to plan for the control and prevention of this disease. 


\section{Objectives}

The study aimed at studying HIV|ADIS high risk behaviors and necessity of prevention in Birjand population, East of Iran.

\section{Methods}

This population-based study was conducted on 5235 subjects with an age range of 15 to 70 years, from Birjand (East of Iran), during years 2013 to 2014. Data was gathered from a comprehensive study performed in Birjand city (8). In brief, multistage sampling method was used. According to the city's postal areas, 250 clusters were identified. In each cluster, equal numbers of subjects were selected to complete the sample size. After explaining the research project, the participants were invited to take part in the study and undergo hepatitis B testing at no cost. All serum samples were tested by commercially available enzymelinked immunosorbent assay (ELISA) kits to detect anti-HIV antibodies (HIVAb; Genscreen® plus HIV Ag-Ab, Bio-Rad, Matnes la coquette, France).

The ethics committee of Birjand University of Medical Sciences approved the ethical considerations of the present study (code: Ir.bums.REC.1394.381). Subjects were asked to complete a checklist including gender (male/female), marital status (single, married, divorced, and widow), history of drug injection (yes/no), history of tattooing (yes/no), unsafe sexual contact (yes/no), history of imprisonment (yes/no), history of dental surgeries (yes/no), history of bloodletting (yes/no), and history of blood transfusion (yes/no). After obtaining the information and ensuring that they were correctly entered in the IBM SPSS software (version 22), descriptive information were presented in counts, percentages, and appropriate figures. The chi-square (or exact Fisher) test was performed and $\mathrm{P}<0.05$ was considered statistically significant.

\section{Results}

Of 5235 subjects, 2503 (52.2\%) were male, 873 (16.7) were single, 4248 (81.1) were married, and $20(0.4 \%)$ were divorced. Descriptive statistics showed that $9(0.2 \%)$ subjects had a history of drug injection, $81(1.5 \%)$ subjects had a history of tattooing, $44(0.8 \%)$ subjects had unsafe sexual contact, 39 (0.7\%) subjects had history of imprisonment, 1709 (32.6\%) subjects had a history of dental surgeries, 802 (15.3\%) subjects had a history of bloodletting, and 196 (3.7\%) subjects had a history of blood transfusion. Fortunately, the prevalence of HIV positive results was zero. Males' prevalent high-risk behaviors were history of dental surgeries (30.8\%) and history of bloodletting (15.8\%). Similarly, females had greater history of dental surgeries (34.3\%) and history of bloodletting (14.9\%). History of drug injection, tattooing, unsafe sexual contact, imprisonment and dental surgeries showed a significant relationship with gender (Table 1).

\section{Discussion}

Epidemiological knowledge of HIV infected subjects, especially in poor resource settings, is essential for policymakers to manage challenges presented by this disease (9). The HIV|AIDS surveillance system was not in direction of second generation HIV surveillance system, which was presented by the world health organization (WHO) (10). Iran, as a developing country, has always had several challenges to implement this WHO program; this is due to a lack of accuracy of collected information (11). Therefore, HIV/AIDS prevalence is commonly underestimated.

This was a population-based study about the prevalence of HIV-related high-risk behaviors in east of Iran, Birjand. Investigation of high-risk behaviors could aid with the prevention of diseases like HIV|AIDS. The findings showed that fortunately the prevalence of HIV positive results was 0 in Birjand, East of Iran, and most prevalent risk behaviors were history of dental surgeries (1709; 32.6\%), history of bloodletting (802; 15.3\%) and history of blood transfusion (196;3.7\%). Males had the highest portion in all high-risk behaviors related to HIV in comparison with females, and history of drug injection, tattooing, unsafe sexual contact, imprisonment, and dental surgeries showed a significant relationship with gender. Makiani et al. indicated that $8.4 \%$ of subjects had reported tattooing, 7.6\% had drug injection, and $10.7 \%$ had unsafe sexual contact in Bandar Abbas, South of Iran (7). This study showed that the prevalence of tattooing, drug injection, and unsafe sexual contact were $1.5 \%, 0.2 \%$, and $0.8 \%$ in Birjand, East of Iran. To the best of our knowledge, most of the Iranian studies have been about the prevalence of HIV|AIDS in injection drug users (IDU), hemophilia patients or prisoners (6, 12-17). Patients, who have HIV|AIDS, are more likely to have stigma, which causes the disease to stay hidden and transfer to others. Therefore, prevention programs need to pay particular attention to psychological aspects of social care and support of HIV-infected patients and prevention of stigmatization, especially in areas where the prevalence of the disease is very low and is much harder for patients to deal with their disease. Doosti-Irani and Holakouie-Naienishows are topics related to knowledge, prevention of HIV/AIDS, adherence to treatment and drug resistance are research priorities in Iran (18). Currently, HIV has no cure, and the only way to remain safe is prevention. However, HIV/AIDS progress is still in controllable level in Middle East and 
Table 1. Frequency of HIV High Risk Behaviors in Both Genders

\begin{tabular}{|c|c|c|c|c|}
\hline Variables & Males $(\mathbf{n}=2503)$ & Females $(n=2732)$ & Total $(n=5235)$ & PValue (Chi-Square or Exact Fisher) \\
\hline History of drug injection & $8(0.3 \%)$ & $1(0.0 \%)$ & $9(0.2 \%)$ & $0.047^{\mathrm{a}}$ \\
\hline History of tattooing & $50(2.0 \%)$ & $31(1.1 \%)$ & $81(1.5 \%)$ & $0.048^{\mathrm{a}}$ \\
\hline Unsafe sexual contact & $40(1.6 \%)$ & $4(0.1 \%)$ & $44(0.8 \%)$ & $<0.001^{\mathrm{a}}$ \\
\hline History of prisoning & $31(1.2 \%)$ & $8(0.3 \%)$ & $39(0.7 \%)$ & $<0.001^{\mathrm{a}}$ \\
\hline History of dental surgeries & $771(30.8 \%)$ & $938(34.3 \%)$ & $1709(32.6 \%)$ & $0.029^{\mathrm{a}}$ \\
\hline History of bloodletting & $396(15.8 \%)$ & $406(14.9 \%)$ & $802(15.3 \%)$ & 0.258 \\
\hline History of blood transfusion & $80(3.2 \%)$ & $116(4.2 \%)$ & $196(3.7 \%)$ & 0.063 \\
\hline
\end{tabular}

${ }^{\mathrm{a}}$ Statistically significant $(\mathrm{P}<0.005)$.

North Africa (MENA) regions, which should not be missed (19).

\subsection{Conclusion}

It is recommended to increase knowledge about HIV|AIDS behaviors, especially in low risk populations. Future researches are recommended to focus on strategies to decrease high-risk behaviors among susceptible individuals.

\section{Acknowledgments}

The authors would like to thank the vice-chancellor of research and technology of Birjand University of Medical Sciences for financial support of this study.

\section{Footnote}

Conflict of Interest: The authors had no conflicts of interest to declare for this study.

\section{References}

1. WHO.. World health statistics 2010. World Health Organization; 2010 .

2. WHO. . World health statistics 2015. ; 2015.

3. Haghdoost . Modelling of HIV/AIDS in Iran up to 2014. Journal of AIDS and HIV Research. 2011;3(12) doi: 10.5897/jahr11.030.

4. Zali MR, Mehr AJ, Rezaian M, Meamar AR, Vaziri S, Mohraz M. Prevalence of intestinal parasitic pathogens among HIV-positive individuals in Iran. Jpn J Infect Dis. 2004;57(6):268-70. [PubMed: 15623953].

5. Noroozi M, Mirzazadeh A, Noroozi A, Mehrabi Y, Hajebi A, Zamani S, et al. Client-Level Coverage of Needle and Syringe Program and HighRisk Injection Behaviors: A Case Study of People Who Inject Drugs in Kermanshah, Iran. Addict Health. 2015;7(3-4):164-73. [PubMed: 26885353].

6. Ghasemzadeh I, Shahri RZ, Namazi SA, Sadeghi P, Shojaeddin S. Review of HIV risk factors in prison inmates in Iran. Life Sci J. 2014;11(4s):236-9.

7. Makiani MJ, Davoodian P, Abedi F, Hossini M, Zare S, Rahimi S, et al. AIDS and hepatitis B and C high risk behaviors among 15 to 45 years old individuals in Bandar Abbas (Iran) in 2012. Electron Physician. 2014;6(3):884-9. doi:10.14661/2014.883-889. [PubMed: 25763163].
8. Ziaee M, Ebrahimzadeh A, Azarkar Z, Namaei MH, Saburi A, Fereidouni M, et al. Seroprevalence and Risk Factors for Hepatitis B in an Adult Population: The First Report from Birjand, South Khorasan, Iran. Hepat Mon. 2016;16(9):e36452. doi: 10.5812/hepatmon.36452. [PubMed: 27822260].

9. Movahedi Z, Mahmoudi S, Pourakbari B, Keshavarz Valian N, Sabouni F, Ramezani A, et al. Epidemiology of children with acquired immune deficiency syndrome (stage 3): A referral hospital-based study in Iran. J Med Virol. 2016;88(1):64-8. doi: 10.1002/jmv.24294. [PubMed: 26512710].

10. Nematollahi M, Khalesi N, Moghaddasi H, Askarian M. Second Generation of HIV Surveillance System: A Pattern for Iran. Iran Red Crescent Med J. 2012;14(5):309-12. [PubMed: 22829992].

11. Rennie S, Turner AN, Mupenda B, Behets F. Conducting unlinked anonymous HIV surveillance in developing countries: ethical, epidemiological, and public health concerns. PLoS Med. 2009;6(1):e4. doi: 10.1371/journal.pmed.1000004. [PubMed: 19166264].

12. KSC. . Review of hiv prevention and care for injection drug users in islamic republic of Iran. World Health Organization; 2005.

13. Zamani S, Kihara M, Gouya MM, Vazirian M, Ono-Kihara M, Razzaghi EM, et al. Prevalence of and factors associated with HIV-1 infection among drug users visiting treatment centers in Tehran, Iran. AIDS. 2005;19(7):709-16. [PubMed: 15821397].

14. Solomon SS, Mehta SH, Latimore A, Srikrishnan AK, Celentano DD. The impact of HIV and high-risk behaviours on the wives of married men who have sex with men and injection drug users: implications for HIV prevention. J Int AIDS Soc. 2010;13 Suppl 2:S7. doi: 10.1186/1758-2652-13S2-S7. [PubMed: 20573289].

15. Ziaee M, Zarban A, Malekinejad P, Akhbary H. Evaluation of HGV viremia prevalence and its co-infection with HBV, HCV, HIV and HTLV1 in hemophilic patients of Southern Khorassan, Iran. Hepat Mon. 2007;7(1):11-4

16. Ziaee M, Sharifzadeh G, Namaee MH, Fereidouni M. Prevalence of HIV and Hepatitis B, C, D Infections and Their Associated Risk Factors among Prisoners in Southern Khorasan Province, Iran. Iran J Public Health. 2014;43(2):229-34. [PubMed: 26060747].

17. Ziaee M, Namaei MH, Azarkar G. The prevalence of HTLV-1 and its CoInfection with HCV, HBV and HIV in Hemophilic patients. PakJMed Sci. 2015;31(5):1246-9. doi:10.12669/pjms.315.7888. [PubMed: 26649023].

18. Doosti-Irani A, Holakouie-Naieni K. Determination the Research Priorities in the Field of HIV/AIDS in Iran: A Systematic Review Article. Iran J Public Health. 2016;45(9):1149-58. [PubMed: 27957460].

19. Gokengin D, Doroudi F, Tohme J, Collins B, Madani N. HIV/AIDS: trends in the Middle East and North Africa region. Int JInfect Dis. 2016;44:6673. doi: 10.1016/j.ijid.2015.11.008. [PubMed: 26948920]. 